\title{
Lisansüstü Tezlerde Bilgisayar Destekli Matematik Öğretimi Uygulamaları: Meta-Sentez Çalışması
}

\section{Computer Assisted Mathematics Teaching in Dissertations: A Meta- Synthesis Study}

\author{
Mesut TABUK*
}

Received: 13 June 2018

Research Article

Accepted: 09 February 2019

\begin{abstract}
The objective of this study is to provide a systematic review of theses and dissertations about computer assisted mathematics teaching and to present a meta-synthesis review of these studies. For the objective of this research study, a total of 64 theses and dissertations completed in Turkey between 1993 and 2016 were included in the systematic review process. Theses and dissertations were examined based on some variables: year of publication, type, university, institution and used computer programs. The results of the systematic review were presented by tables including frequencies and percentages. As a result of the study, it was found that majority of researches were presented after the year 2008 and as master thesis at educational science graduate school. In addition, computer software for teaching mathematics, computer algebra systems (CAS) and dynamic mathematics software (DMS) were used most commonly as a computer assisted teaching application. It is hoped that the results of the study will provide a guidance for mathematics educators, and researchers for new researches in the future. According to these obtained results, some recommendations were made for mathematics educators, and researchers. It is also especially recommended that a similar study be repeated in every five years in Turkey in order to monitor and review the research trends.
\end{abstract}

Keywords: computer-assisted, mathematics teaching, meta-synthesis, theses and dissertations.

ÖZ: $\mathrm{Bu}$ çalışmanın amacı bilgisayar destekli matematik öğretimi ile ilgili yapılmış tezlerin sistematik bir incelemesini yapmak ve yapılan bu araştırmalar üzerine bir tematik içerik analizi (meta-sentez) gerçekleştirmektir. Bu amaç doğrultusunda, Türkiye'de 1993 ve 2016 yılları arasında yayımlanan toplam 64 lisansüstü tez içerik analizi sürecine dâhil edilmiştir. Tezler, yayım yılı, tür, üniversite, enstitü ve kullanılan bilgisayar uygulamaları gibi değişkenlere göre incelenmiştir. Meta-senteze ait sonuçlar, frekans ve yüzde oranları içeren tablolarla sunulmuştur. Araştırma sonucunda, tezlerin çoğunluğunun 2008 yılından sonra yazıldığı ve eğitim bilimleri enstitülerinde yüksek lisans tezi olarak sunulduğu görülmüştür. Ayrıca öğretici yazılımların, bilgisayar cebir sistemlerinin (BCS) ve dinamik matematik yazılımlarının (DMY) en sık kullanılan bilgisayar destekli matematik öğretimi uygulamaları olduğu belirlenmiştir. Araştırmadan elde edilen sonuçların, gelecekte yeni araştırmalarda matematik eğitimcileri ve araştırmacılar için bir rehberlik sağlayacağı umulmaktadır. Elde edilen bu sonuçlara göre, matematik eğitimcileri ve araştırmacılar için bazı önerilerde bulunulmuştur. Araştırma eğilimlerinin izlenmesi ve gözden geçirilmesine yönelik benzer içerik analizi çalışmalarının Türkiye'de her beş yılda bir tekrarlanması özellikle önerilmektedir.

Anahtar kelimeler: bilgisayar destekli, matematik öğretimi, meta-sentez, lisansüstü tezler.

Corresponding Author: Asst. Prof. Dr., Canakkale Onsekiz Mart University, Canakkale, Turkey, mesuttabuk@,comu.edu.tr, https://orcid.org/0000-0003-1547-3073

Citation Information

Tabuk, M. (2019). Lisansüstü tezlerde bilgisayar destekli matematik öğretimi uygulamaları: Meta-sentez çalışması. Kuramsal Eğitimbilim Dergisi [Journal of Theoretical Educational Science], 12(2), 656-677. 


\section{Giriş}

\section{Eğitim Alanında Yapılan Çalışmaların Değerlendirilmesi}

Eğitim alanında Türkiye'de yapılan akademik çalışmaların sayısında ve çeşitliliğinde son yıllarda önemli bir artışın olduğu gözlemlenmektedir. Bu konuda yapılan bir araştırmaya göre 1997 ve 2014 yılları arasında Social Science Citation Index (SSCI) kapsamında yer alan dergilerde toplamda dört binden fazla yayın yer almış ve bu yayın sayısı özellikle 2001 yılından sonra hızla artış göstermiştir. 2012 yılında ise bu sayı zirveye ulaşmıştır (Çalık \& Sözbilir, 2015). Yine uluslararası düzeyde yapılan başka bir çalışmada ise 148 ülke içerisinde, Türkiye 1990 ile 1994 yılları arasında yayımlanan eğitim araştırmaları sayısına göre otuz üçüncü sırada yer alırken, bu sıralama 2005 ve 2009 yılları arasında altıncılığa ve 2011 yılında üçüncülüğe kadar yükselmiştir (Tseng, Chang, Tutwiler, Lin, \& Barufaldi, 2013).

Türkiye'de genel olarak eğitim alanında ve özellikle de matematik eğitimi alanında yayımlanmış çalışmaların sayısı 1990'lı yıllarda eğitim sisteminde gerçekleştirilen yenilenme çalışmalarından sonra ciddi artış göstermiştir (Çiltaş, Güler, \& Sözbilir, 2012). Yapılan bu çalışmaların konu ile ilgili çalışma yapacak araştırmacılara yol göstermek amacı ile sistemli bir şekilde değerlendirilmesine yönelik ihtiyaç alanyazında vurgulanmakta ve bu amaçla bazı çalışmalar ortaya konmaktadır (Çalık \& Sözbilir, 2014; Çiltaş, Güler, \& Sözbilir, 2012; Göktaş ve diğerleri, 2012). Bu sistemli inceleme çalışmaları, genel olarak içerik analizi çalışmaları olarak isimlendirilmekte ve betimsel analiz, meta-sentez ve meta-analiz olmak üzere üç başlık altında ele alınmaktadır (Çalık \& Sözbilir, 2014). Alanyazında meta-analiz, meta-sentez ve betimsel içerik analizi kavramlarının bazen birbirleri yerine kullanıldığı ve bu durumun karışıklığa sebep olduğu vurgulanmaktadır (Dinçer, 2018). Çalışma temel olarak nitel bulgulara ait yorumlarının analizine yer veren bir meta-sentez çalışmasıdır (Çalık \& Sözbilir, 2014; Dinçer, 2018).

\section{Matematik Eğitimi Alanında Yapılmış Çalışmaların Değerlendirilmesi}

Genel olarak eğitim alanındaki çalışma sayısında yaşanan dikkat çekici artış eğitimin alt alanlarında da özellikle de matematik eğitimi alanında da gözlemlenmektedir. Matematik eğitimi alanında Ulutaş ve Ubuz (2008) tarafından gerçekleştirilen çalışmada 2000 ile 2006 yılları arasında yayımlanmış 129 makale incelenmiş ve bu artışı gösteren tespitler ortaya konmuştur. Çalışma sonuçlarına göre 2000 ve 2001 yıllarında toplam 11 yayım yapılmışken 2002 ve sonrasında bu sayı her yıl yirminin üzerinde gerçekleşmiştir.

Çiltaş (2012), matematik eğitimi alanında yaptı̆̆ı içerik analizi çalışmasında 2005 ve 2010 yılları arasında ortaya konan lisansüstü tezleri incelemiştir. Doktora ve yüksek lisans tezleri olmak üzere 150 lisansüstü tezin incelendiği çalışmanın sonuçlarına göre; 2005 ve 2006 yıllarında yedişer ve 2007 yılında ise 27 tez çalışması yapılmıştır. Ayrıca daha önceki üç yılda toplam 41 tez çalışması yapılmasına rağmen sadece 2008 yılında 52 tez çalışması ortaya konmuştur.

Matematik eğitimi alanında yapılmış daha geniş kapsamlı bir diğer çalışma ise Çiltaş, Güler ve Sözbilir (2012) tarafından yapılmıştır. 1987 ile 2009 yılları arasında, ulusal ve uluslararası 32 dergiden 359 makalenin içerik analizi yöntemi kullanılarak 
incelendiği çalışmanın sonuçlarına göre 2001 yılı ve öncesi 14 yıllık dönemde toplam 33 çalışma yer alırken bu sayı 2002 yılında 20 ve 2003 yılında ise yıllık 33'e ulaşmıştır. Çalışma sayısının zirveye ulaştığı 2005 ve 2006 yıllarında ise sırası ile yıllık 55 ve 56 çalışma ortaya konmuştur.

Görüldüğü gibi matematik eğitimi alanında son yıllarda yapılan çalışmaların sayısındaki önemli artış bu değerlendirme çalışmalarında da ortak bir şekilde vurgulanmaktadır. Bu artışa bağlı olarak matematik eğitimi alanında güncel durumun belirlenmesi adına benzer çalışmaların belli aralıklarla tekrar edilmesi gerektiği önerilmektedir (Çiltaş, 2012). Bu çalışmalar sayesinde matematik eğitimi alanında yapılan çalışmaları bir bütün olarak görebilmek mümkün olabilmektedir. Matematik eğitimi alanındaki çalışma sayısı arttıkça yeni yapılacak değerlendirme ve inceleme çalışmalarının daha dar kapsamlı konular üzerine ve daha detaylı gerçekleştirilmesi önerilen bir başlık olarak karşımıza çıkmaktadır (Ulutaş \& Ubuz, 2008).

Matematik eğitimi alanında yapılan içerik analizi çalışmalarında en sık yer verilen alt başlıklardan birinin bilgisayar destekli matematik öğretimi (BDMÖ) olduğu görülmektedir. Ulutaş ve Ubuz (2008) yaptıkları çalışma sonucunda matematik eğitimi alanında yapılan çalışmalarda en sık kullanılan öğretim yönteminin BDMÖ olduğunu belirtmektedir. Yine Çiltaş, Güler ve Sözbilir (2012) ve Çiltaş (2012) da matematik eğitiminde en sık çalışılan konulardan birinin BDMÖ olduğunu vurgulamaktadırlar. Tatar ve Tatar (2008) ise matematik eğitimi alanında yapılan çalışmalarda en sık kullanılan 37 anahtar kelime içinde BDMÖ'nün altıncı sırada yer aldığını göstermektedir.

\section{Bilgisayarların Gelişimi ve Eğitim Alanında Kullanımı}

Günümüzde, gerek ülkemizde gerekse dünyada bilgisayarların toplumda yaygınlaşması baş döndüren bir hızla gerçekleşmektedir. Türkiye İstatistik Kurumu (TÜIK) tarafından en son yayımlanan hanelerde bilişim teknolojilerinin bulunması ile ilgili veriler bu konuda önemli kanıtlar sunmaktadır. 2004 yılında Türkiye'de hanelerin sadece \%10.9'unda masaüstü veya taşınabilir bilgisayar varken 2017 yılı itibari ile evlerin \%87.7'sinde masaüstü veya taşınabilir bilgisayar (Laptop, Tablet PC veya netbook) bulunmaktadır (TÜİK, 2017). Eğitim alanında ise özellikle Fırsatları Artırma ve Teknolojiyi İyileştirme Hareketi (FATİH) isimli projenin 2010 yılında başlatılması ile bilgisayarların eğitim ve öğretim alanındaki önemi göze çarpan bir şekilde ön plana çıkmıştır.

Bilgisayar kavramı sözlük anlamı olarak "çok sayıda aritmetiksel veya mantıksal işlemlerden oluşan bir işi, önceden verilmiş bir programa göre yapıp sonuçlandıran elektronik araç, elektronik beyin" olarak tanımlanmaktadır (Türk Dil Kurumu [TDK], 2018). Bilgisayarların tarihsel gelişim süreci incelendiğinde başlangıç noktasını MÖ 3000'li y1llarda Babil'de kullanılmış ilk toplama makinesi olan abaküse kadar geriye götürmek mümkündür. 1642 yılında Blaise Pascal tarafından geliştirilen toplama ve çıkarma işlemlerini yapabilen "Pascalline" adlı hesap makinesi ise bu gelişim sürecini takip ederken dikkat çeken bir diğer önemli kırılma noktasıdır (Özçep ve diğerleri, 2003).

Bilgisayarlar ile ilgili ciddi çalışmalardan bir diğeri ise Charles Babbage tarafından 1830 yılında geliştirilmiş olan "Diferans makinesi" olmuştur. Bu makinenin çalışma sistemi günümüzde kullandığımız bilgisayarlarının çalışma prensiplerine 
oldukça benzemektedir. Makine delikli kartlarla çalışıyordu. Diferans makinesi, bu kartları okuyor, anlamlandırıyor, değişik problemleri kaydediyor ve cevabı kâğıt üzerine yazdırabiliyordu. Babbage makinenin daha gelişmiş bir modeli üzerinde yaptığ çalışmaları tamamlayamadan öldü. Fakat onun bilgisayar alanında dikkate değer bu çalışması ve tamamlayamasa da geliştirdiği fikirleri "Bilgisayarın babası" olarak anılmasını sağladı (Hyman, 1982). Günümüz modern bilgisayarlarının ilk örneği olan ilk elektronik bilgisayar ise 1943 yılında geliştirilen ENIAC olmuştur. Yaklaşık 6 metre eninde 12 metre boyunda bir odayı kaplayan 30 ton ağırlığındaki bu makine 20 basamaklı sayılara kadar işlem yapabiliyordu (Singh \& Singh, 2016).

Bilgisayarların ilk defa eğitim kurumlarına girmesi 1950'li yılların sonunu bulmuştur. Bilgisayarların maliyetinin 1960'l yılların sonu ve 1970'li yıllarda azalması ile uygulamaya konan IBM 1500, PLATO ve TICCIT gibi projelerle geleneksel

öğretime destek olmak amacıyla eğitim kurumlarında bilgisayar kullanımının yaygınlaşması sağlanmıştır (Ergün, 1998). Türkiye'de bilgisayarların kullanımı ilk olarak 1960 yılında Karayolları Genel Müdürlüğü bünyesine dâhil edilen "IBM- 650 Data Processing Machine" olarak adlandırılan makinelerin kullanımı ile başlamıştır. Bu gelişmenin bir sonucu olarak 1987 y1lından itibaren gündeme gelen bilgisayar destekli eğitim (BDE) ile bilgisayar destekli öğretim (BDÖ) kavramları sorgulanmaya ve akademik anlamda irdelenmeye başlanmıştır. (Engin, Tösten, \& Kaya, 2010). Alanyazında bilgisayar destekli öğretim için yapılmış farklı tanımlar bulunmaktadır. En yaygın yer verilen tanımlamaya göre bilgisayar destekli öğretim; “öğrencinin karşılıklı etkileşim yoluyla eksiklerini ve performansını tanımasını, dönütler alarak kendi öğrenmesini kontrol altına almasını; grafik, ses, animasyon ve şekiller yardımıyla derse karşı daha ilgili olmasını sağlamak amacıyla eğitim-öğretim sürecinde, bilgisayardan yararlanma yöntemi” olarak tanımlanmaktadır (Baki, 2002).

\section{BDMÖ ile İlgili Değerlendirme Çalışmaları}

BDMÖ ile ilgili olarak alanyazında yapılmış bazı inceleme ve değerlendirme çalışmalarına rastlanmaktadır. Açıkgül ve Aslaner (2014), tarafından ortaya konan çalışmada matematik öğretmen adaylarıyla yapılmış bilgisayar destekli matematik öğretimi çalışmalarına yönelik bir literatür incelemesi gerçekleştirilmiştir. Çalışmada 6 tanesi tez olmak üzere toplam 36 çalışma incelenmiştir. Çalışmada incelenen araştırmalar yayımlandığı dil ve yıl, araştırmanın konusu ve deseni, araştırmanın yapıldığı düzey ve araştırmada kullanılan veri toplama araçları olmak üzere altı başlık altında incelenmiştir. Araştırma sonuçlarına göre, toplam 36 çalışmanın 13 tanesinin yapıldığı 2008 en çok çalışma yapılan yıl olurken; çalışmaların 28 tanesi Türkçe ve 8 tanesi ise İngilizce yayımlanmıştır. En sık çalışılan konu; öğretmen adaylarının tutum ve görüşleridir. Yöntem olarak nitel yöntem en çok kullanılan yöntem olurken, düzey olarak ise son sınıf düzeyi tercih edilmiştir. Veri toplama araçlarında ise gözlem ve anket en çok başvurulan veri toplama araçları olmuştur.

Demir ve Başol (2014) tarafından gerçekleştirilen matematik dersinde BDMÖ’nün akademik başarı üzerindeki etkisinin belirlenmeye çalışıldığ1 meta-analiz çalışmasına ise toplam 40 çalışma dâhil edilmiştir. Bu 40 çalışma lisansüstü tezler, makaleler ve bildirilerden oluşmaktadır. Araştırma sonuçları BDMÖ’nün akademik başarı üzerinde istatistiksel açıdan anlamlı, pozitif yönde ve geniş ölçüde etkisinin olduğunu ortaya koymuştur. 
Kutluca, Hacıömeroğlu ve Gündüz (2016) tarafından yapılan bir diğer çalışmada ise BDMÖ üzerine gerçekleştirilmiş 99 lisansüstü tez incelenmiştir. Tezlerin yayım yılı, tez türü, modeli ve örneklemi gibi farklı özellikleri ele alınarak analiz edilmiştir. Sonuç olarak tezlerin çoğunun 2008 yılı ve sonrasında gerçekleştirildiği, ağırlıklı olarak yüksek lisans tezleri olduğu ve genellikle ilköğretim öğrencileri ile çalışıldığ belirlenmiştir.

\section{Araştırmanın Amacı ve Önemi}

Alanyazında BDMÖ ile ilgili olarak yapılmış meta-analiz (Demir \& Başol, 2014), literatür incelemesi (Açıkgül \& Aslaner, 2014), değerlendirme çalışması (Kutluca, Hacıömeroğlu \& Gündüz, 2016) ve bazı başka çalışmalar (Gürsoy, 2017) mevcuttur. Mevcut olan çalışmalarda BDMÖ’nün oldukça geniş çerçevede ele alındı ğ görülmektedir. Anahtar kelime olarak BDMÖ içeren dinamik matematik veya geometri yazılımlarının kullanıldığ bazı çalışmalar kısmen bu araştırmalara dâhil edilmiştir. Yine BDMÖ kapsamında farklı paket program ve uygulamaların kullanıldığı çalışmalara da yer verildiği görülmektedir. Fakat bu başlıklar ile ilgili tüm araştırmalar kapsanmamıştır. Bu noktada BDMÖ denildiğinde ne anlaşılması gerektiği konusunda bir kafa karışıklığı bulunmaktadır. Bu karışıklığı bir dereceye kadar ortadan kaldırabilmek adına araştırmamıza sadece BDMÖ üzerine yapılıı̧̧ çalışmalar dâhil edilmiştir.

Çalışmanın genel amacı ise, Türkiye'de BDMÖ üzerine yapılmış lisansüstü tezler ile ilgili genel durumu değerlendirmek ve mevcut bilgileri belli temalar çerçevesinde sistematik bir şekilde sunmak olarak belirlenmiştir. Bu genel amaca yönelik olarak aşağıdaki araştırma sorularına cevaplar aranmıştır.

1. Türkiye'de BDMÖ üzerine yapılan lisansüstü tezlerin türüne ve yayım yılına göre dağılımı nasıldır?

2. Türkiye'de BDMÖ üzerine yapılan lisansüstü tezlerin yayımlandığı üniversite ve enstitüye göre dağılımı nasıldır?

3. Türkiye'de BDMÖ üzerine yapılan lisansüstü tezlerde kullanılan bilgisayar uygulamalarının dağılımı nasıldır?

\section{Yöntem}

\section{Araştırma Modeli}

$\mathrm{Bu}$ çalışma Türkiye'de BDMÖ üzerine yapılmış lisansüstü tezlerinin incelenmesi amacıyla meta-sentez yönteminin kullanıldığı tarama modelinde bir araştırmadır. İçerik analizi çalışmaları; betimsel analiz, meta-sentez ve meta-analiz olmak üzere üç başlık altında toplanmaktadır. Meta-sentez, bir konu üzerinde ortaya konmuş araştırmaların belirli temalar veya ana şablonlar çerçevesinde eleştirel bir bakış açısı ile incelenmesi, sentezlenmesi ve yorumlanması olarak tanımlanmaktadır (Çalık \& Sözbilir, 2014).

\section{Çalışmaların Araştırmaya Dâhil Edilme Ölçütleri}

Çalışmaya, Türkiye'de 1993-2016 yılları arasında BDMÖ ile ilgili olarak yapılmış lisansüstü tezler dâhil edilmiştir. Tezlere YÖK tez merkezinde 2018 yılı Mayıs ayı içinde yapılan tarama sonucu ulaşılmıştır. Tez arama motorunda "bilgisayar destekli 
eğitim”, "bilgisayar destekli öğretim”, “computer aided/assisted education”, “computer aided/assisted teaching" ve "computer aided/assisted learning" anahtar kelimeleri ile yapılan tarama sonucu ulaşılan matematik eğitimi alanındaki tezler çalışma kapsamına alınmıştır. Çalışma kapsamına alınacak tezler için aşağıda sıralanan seçim ölçütleri kullanılmıştır.

- YÖK tez merkezinde yayımlanmış yüksek lisans veya doktora tezi olması

- Başlığının "bilgisayar destekli eğitim”, “bilgisayar destekli öğretim”, "computer aided/assisted education", "computer aided/assisted teaching" ve "computer aided/assisted learning”anahtar kelimesini içermesi

- Matematik eğitimi alanında yapılmış olması

- Erişime açık olması ya da tam metnine ulaşılıyor olması

\section{Araştırmaya Dâhil Edilen Çalışmalar ve Kodlama Süreci}

Yapılan bu araştırma ve değerlendirme sonucu çalışma kapsamında incelenen 55 tanesi yüksek lisans ve 9 tanesi doktora tezi olmak üzere toplam 64 lisansüstü tez Ek1 'de yer alan listede sıralanmıştır. Yukarıda belirtilen seçim ölçütlerine göre araştırma kapsamına alınan çalışmalar Ek-2'de yer alan “Tez Değerlendirme Formu” kullanılarak kodlama sürecine alınmıştır. Değerlendirme formu Sözbilir, Kutu ve Yaşar (2012) tarafından geliştirilen "Makale Sınıflama Formu" tez yapısına göre yeniden düzenlenerek hazırlanmıştır.

\section{Verilerin Analizi}

Araştırma kapsamında içerik analizine alınan BDMÖ üzerine yapılmış tez çalışmaları ile ilgili elde edilen bulgular, araştırmanın yöntemi ve araştırma soruları göz önünde bulundurularak sunulmuştur. $\mathrm{Bu}$ çerçevede belirlenen temalar ile ilgili ilk adımda kodlama işlemi gerçekleştirilmiş ve sonrasında analiz çalışmalarına gidilmiştir. Elde edilen bulgulara SPSS 21 ve Excel paket programları kullanılarak ulaşılmıştır. Sonuçlar elde edilen frekanslar ve yüzdeler gibi betimsel istatistikler tablolar halinde sunulmuştur.

\section{Bulgular}

Çalışmaya dâhil edilen BDMÖ üzerine yapılmış 64 lisansüstü tez ile ilgili içerik analizine ait bulgular belirlenen araştırma soruları çerçevesinde 4 başlık altında sunulmuştur.

\section{Yayım Yılına Göre Tezlerin Dağılımı}

Çalışma kapsamında incelenen BDMÖ üzerine yapılmış yüksek lisans ve doktora tezlerinin yayım yılına göre dağılımı Tablo 1'de verilmiştir. 
Tablo 1

Yayım Yılına Göre Tezlerin Dă̆ılımı

\begin{tabular}{|c|c|c|c|c|}
\hline & Yüksek Lisans & Doktora & \multicolumn{2}{|c|}{ Toplam } \\
\hline Yillar & $f$ & $f$ & $f$ & $\%$ \\
\hline 1993 & 1 & 0 & 1 & 1.6 \\
\hline 1998 & 1 & 0 & 1 & 1.6 \\
\hline 1999 & 0 & 1 & 1 & 1.6 \\
\hline 2000 & 1 & 0 & 1 & 1.6 \\
\hline 2002 & 2 & 0 & 2 & 3.1 \\
\hline 2003 & 1 & 0 & 1 & 1.6 \\
\hline 2004 & 1 & 0 & 1 & 1.6 \\
\hline 2005 & 3 & 0 & 3 & 4.6 \\
\hline 2006 & 3 & 0 & 3 & 4.6 \\
\hline 2007 & 2 & 0 & 2 & 3.1 \\
\hline 2008 & 7 & 1 & 8 & 12.5 \\
\hline 2009 & 4 & 2 & 6 & 9.4 \\
\hline 2010 & 6 & 0 & 6 & 9.4 \\
\hline 2011 & 7 & 2 & 9 & 14 \\
\hline 2012 & 3 & 0 & 3 & 4.6 \\
\hline 2013 & 5 & 0 & 5 & 7.8 \\
\hline 2014 & 4 & 0 & 4 & 6.3 \\
\hline 2015 & 3 & 1 & 4 & 6.3 \\
\hline 2016 & 1 & 2 & 3 & 4.7 \\
\hline Toplam & $55(\% 85.9)$ & $9(\% 14.1)$ & 64 & 100 \\
\hline
\end{tabular}

Tablo 1'de görüldügü üzere BDMÖ ile ilgili yapılan çalışmalar 2008 yılından itibaren artış göstermiştir. Yapılan çalışma sayısı 2011 yılında yapılan 7'si yüksek lisans ve 2'si doktora tezi olmak üzere toplam 9 lisansüstü tez çalışması ile zirve yapmış (\%14), bu sayı sonraki yıllarda azalma göstermiştir. Yapılan 64 lisansüstü tez çalışmasının 55 tanesi (\%85.9) yüksek lisans düzeyinde iken doktora düzeyindeki çalışmaların sayısı 9 tanedir (\%14.1). Ayrıca toplam sayısı 64 olan lisansüstü tez çalışmalarının neredeyse yarısı yani 29 (\%45.2) tanesi 2008 ve 2011 yılları arasındaki 3 yıllık zaman süresinde yapılmıştır.

\section{Üniversite ve Enstitüye Göre Tezlerin Dağılımı}

Araştırma kapsamına alınan BDMÖ ile ilgili tezlerin hazırlandığı üniversite ve enstitülere göre dağılımı Tablo 2'de verilmiştir. 
Tablo 2

Üniversite ve Enstitülere Göre Tezlerin Dă̆glımı

Enstitüler

Toplam

\begin{tabular}{lcccccc}
\hline Üniversiteler & $\begin{array}{c}\text { Fen } \\
\text { Bilimleri }\end{array}$ & $\begin{array}{c}\text { Eğitim } \\
\text { Bilimleri }\end{array}$ & $\begin{array}{c}\text { Sosyal } \\
\text { Bilimler }\end{array}$ & Diğer & $f$ & $\%$ \\
\hline Gazi Üniversitesi & 0 & 10 & 0 & 0 & 10 & 15.6 \\
Atatürk Üniversitesi & 2 & 7 & 0 & 0 & 9 & 14.1 \\
Marmara Üniversitesi & 1 & 4 & 0 & 0 & 5 & 7.8 \\
Çukurova Üniversitesi & 0 & 0 & 4 & 0 & 4 & 6.3 \\
Balıkesir Üniversitesi & 4 & 0 & 0 & 0 & 4 & 6.3 \\
Eskişehir Osmangazi & 3 & 1 & 0 & 0 & 4 & 6.3 \\
ODTÜ & 1 & 1 & 1 & 1 & 4 & 6.3 \\
KTÜ & 2 & 1 & 0 & 0 & 3 & 4.7 \\
Selçuk Üniversitesi & 1 & 1 & 1 & 0 & 3 & 4.7 \\
Ege Üniversitesi & 2 & 0 & 1 & 0 & 3 & 4.7 \\
Sakarya Üniversitesi & 0 & 1 & 2 & 0 & 3 & 4.7 \\
Diğer & 4 & 3 & 5 & 0 & 12 & 18.5 \\
\hline Toplam & $20(\% 31.2)$ & $29(\% 45.3)$ & $14(\% 21.9)$ & $1(\% 1.6)$ & $64(\% 100)$ & 100
\end{tabular}

Tablo 2'de araştırma kapsamında incelenen 64 lisansüstü tezin hazırlandığ enstitü ve üniversiteye göre dağılımı verilmiştir. Tezlerin üniversitelere göre dağglımı incelendiğinde 23 farklı üniversiteden üretildiği görülmektedir. Üniversiteler sinıflandırılırken 3'ten daha az sayıda tez hazırlanan üniversiteler "diğer" şeklinde yazılırken 3 ve 3 'ten fazla sayıda tez hazırlanan üniversiteler ise ismi ile verilmiştir. Tablo 3 'te hazırlanan lisansüstü tezlerin üniversitelere göre dağılımına bakıldığında en çok Gazi Üniversitesi’nde 10 (\%15.6) lisansüstü tez hazırlanmıştır. İkinci sırada 9 (\%14.1) lisansüstü tez ile Atatürk Üniversitesi, üçüncü sırada ise 5 (\%7.8) lisansüstü tez ile Marmara Üniversitesi vardır. Lisansüstü tezlerin enstitülere göre dağılımı incelendiğinde ise eğitim bilimleri enstitüsü 29 (\%45.3), fen bilimleri enstitüsü 20 (\%31.2) ve sosyal bilimler enstitüsü ise 14 (\%21.9) lisansüstü tez şeklinde siralanmaktadır. Bununla beraber 12 üniversiteden ise sadece birer adet lisansüstü tez çalışmaya dâhil edilmiştir.

\section{Tezlerde Kullanılan Bilgisayar Uygulamalarının Dağılımı}

BDMÖ üzerine yapılan tez çalışmalarında kullanılan bilgisayar uygulamaları incelendiğinde farklı yazılımların kullanıldığı görülmektedir. Bazı tez çalışmalarından birden fazla uygulamanın yer aldığı görülmektedir. Bilgisayar uygulamalarının büyük çoğunluğu alanyazında öğretici yazılımlar olarak sınıflandırılan bilgisayar programlarından oluşmaktadır. Bu yazılımların bir kısmı firmalar tarafından üretilmiş hazır programlardan oluşurken bir kısmı araştırmacılar tarafından geliştirilen programlardır. Bu öğretici yazılımların yanı sıra bazı programlama dilleri, BCS, DMY 
ve Microsoft PowerPoint programı ile hazırlanmış sunular kullanılan diğer bilgisayar uygulamalarıdır. Bu uygulamaların neler olduğu ve tezlerde yer alma sıklıkları Tablo 3 'te verilmiştir.

Tablo 3

Bilgisayar Uygulamalarına Göre Tezlerin Dă̆ılımı

\begin{tabular}{|c|c|c|c|}
\hline Uygulamalar & & $f$ & $f$ \\
\hline \multirow{2}{*}{ Öğretici yazılımlar } & Hazır programlar & 18 & \multirow{2}{*}{38} \\
\hline & Geliştirilen programlar & 20 & \\
\hline \multirow{4}{*}{$\begin{array}{l}\text { Dinamik matematik yazılımları } \\
\text { (DMY) }\end{array}$} & Geogebra & 7 & \multirow{4}{*}{1} \\
\hline & Geometer's Skechpad & 7 & \\
\hline & Cabri & 3 & \\
\hline & Tinkerplots & 1 & \\
\hline \multirow{2}{*}{ Bilgisayar cebir sistemleri (BCS) } & Wolfram Mathematica & 4 & \multirow{2}{*}{6} \\
\hline & Drive & 2 & \\
\hline Microsoft PowerPoint & Sunu & 9 & 9 \\
\hline Programlama dilleri & & 5 & 5 \\
\hline
\end{tabular}

Tablo 3'e göre tezlerde en sık kullanılan uygulamanın 38 tezde kullanılan öğretici yazılımlar olduğu görülmektedir. 20 tezde kullanılan öğretici yazılımların araştırmacılar tarafindan Macromedia Authorware, Macromedia Flash ve Adobe Flash gibi yazılımlar kullanılarak hazırlandığı görülmektedir. Diğer taraftan 18 tez çalışmasında ise firmaların hazırladığı öğretici yazılımların tercih edildiği görülmektedir. Bu yazılımlar arasında en sık kullanılanı ise 8 tez çalışmasında tercih edilen Vitamin programı olmuştur.

Diğer taraftan yine Tablo 3'te yer alan verilere göre en sık kullanılan ikinci uygulama çeşidinin ise DMY olduğu görülmektedir. Toplam 18 tez çalışmasında DMY uygulaması kullanılmıştır. 7'şer tez çalışmasında Geogebra ve Geometer's Skechpad programları kullanılırken 3 çalışmada Cabri ve 1 çalışmada ise Tinkerplots programları kullanılmıştır. Bir diğer BDMÖ uygulama çeşidinin ise 6 tez çalışmasında kullanılan BCS olduğu görülmektedir. Bu 6 çalışmanın 4'ünde Wolfram Mathematica programı kullanılırken 2 çalışmada ise Drive programına yer verilmiştir. Son olarak toplan 9 tez çalışmasında Microsoft PowerPoint programı ile hazırlanmış sunulardan yararlanılırken 5 tez çalışmasında ise BDMÖ uygulaması olarak Logo ve Coypu gibi programlama dilleri kullanılmıştır. Öğretici yazılımların kullanımı ile ilgili diğer detaylar Tablo 4'te sunulmuştur. 
Tablo 4

Tezlerde kullanılan öğretici yazılım uygulamaları

\begin{tabular}{llll}
\hline Öğretici yazılımlar & \multicolumn{1}{c}{$f$} & $f$ \\
\hline \multirow{2}{*}{ Hazır programlar } & Vitamin & 8 \\
\cline { 2 - 3 } & Diğerleri & 18 \\
\hline Meliştirilen programlar & Macromedia Authorware & 2 \\
\cline { 2 - 3 } & Macromedia Flash & 6 \\
\cline { 2 - 3 } & Adobe Flash & 6 \\
\cline { 2 - 3 } & Diğer & 6 \\
\hline
\end{tabular}

Tablo 4'e göre 18 tezde yer verilen öğretici yazılımlar arasında en sık kullanılan hazır programın 8 tez çalışmasında tercih edilen Vitamin programı olduğu görülmektedir. Çalışmaların bazılarında programın CD ortamında sunulan uygulaması tercih edilirken bazı çalışmalarda ise web tabanlı uygulaması kullanılmıştır. Ayrıca Bilden, EBA, Morpa, Frizbi Matematik, Wingeom-tr ve EveryDay Mathematics gibi uygulamalar ise birer tez çalışmasında kullanılmıştır. Bunların dışında ise bazı çalışmalarda ismi verilmeyen farklı öğretici bilgisayar yazılımlarının kullanıldığı görülmektedir.

Ayrıca 20 tez çalışmasında araştırmacılar kendi öğretici bilgisayar uygulamalarını geliştirmişlerdir. Uygulama geliştirme aracı olarak en s1k tercih edilen programlar ise 6'şar tez çalışmasında kullanılan Macromedia Flash ve Adobe Flash programları olmuştur. Bu iki program dişında 2 tezde ise araştırmacılar Macromedia Authorware programından faydalanmışlardır. Ayrıca birer tez çalışmasında BDMÖ uygulamaları C++, Inspiration, R programı, 3DS MAX ve UNITY3D yazılımları kullanılmıştır. Bazı çalışmalarda ise araştırmacılar uygulamaları geliştirdikleri programların detaylarını paylaşmamışlardır.

\section{Sonuç ve Tartışma}

$\mathrm{Bu}$ çalışma, BDMÖ ile ilgili olarak hazırlanmış 64 lisansüstü tezi kapsayan bir meta-sentez çalışmasıdır. Çalışmanın bu kısmında, gerçekleştirilen içerik analizinden elde edilen bulgular 1şığında ortaya konan sonuçlar tartışılmış ve bazı önerilere yer verilmiştir.

2008 yılından önce BDMÖ ile ilgili yapılan çalışmalar sadece 16 tane iken 2008 yılından itibaren yapılan 8 tez çalışması ile beraber bu sayı artış göstermiştir. 2011 y1lında ise 7'si yüksek lisans ve 2'si doktora tezi olmak üzere toplam 9 lisansüstü tez çalışması ile bu sayı zirveye ulaşmış sonraki yıllarda ise nispi bir azalma gerçekleşmiştir. Demir ve Başol (2014) tarafından ortaya konan ve 2002-2011 y1lları arasındaki tezlerin incelendiği çalışmada da benzer bir şekilde 2011 yılına kadar yapılan tez sayısında sürekli artış olduğu sonucu elde edilmiştir. Diğer iki çalışmada ise çalışma sayısındaki azalma 2008 yılından itibaren gerçekleşmiştir (Açıkgül \& Aslaner, 2014; Kutluca, Hacıömeroğlu, \& Gündüz, 2016). Çalışma sayılarında son yıllarda gerçekleşen azalışın sebebi ise BDMÖ üzerine yapılan araştırmaların daha dar kapsamda ele 
alınarak BCS, DMY ve akıllı tahta uygulamaları gibi daha özel çalışmaların sayısındaki artışla açıklanabilir.

Çalışma kapsamında ele alınan 64 tez çalışmasının büyük bir kısmı yüksek lisans düzeyinde iken doktora düzeyindeki çalışmaların sayısının sadece 9 olduğu sonucuna ulaşılmıştır. Benzer sonuçlar diğer çalışma sonuçlarıyla da desteklenmektedir. Demir ve Başol (2014) tarafından yapılan çalışmada 20 tezden 16 tanesi ve Kutluca, Hacıömeroğlu ve Gündüz (2016) tarafından yapılan çalışmada ise 99 tezden 90 tanesinin yüksek lisans tezi olduğu görülmektedir. YÖK tez merkezinde eğitim ve öğretim konulu tezler incelendiğinde de yüksek lisans tezlerinin sayısı 32466 iken doktora tezlerinin sayısının sadece 6945 olduğu görülmektedir. Bu noktada yüksek lisans tezlerinin doktora tezlerine göre sayıca yüksek çıkması olağan bir durum olarak kabul edilebilir.

Hazırlanan tezlerin üniversitelere ve enstitülere göre dağılımına bakıldığında yapılan diğer çalışmaların sonuçları ile benzerlikler görülmektedir (Kutluca, Hacıömeroğlu, \& Gündüz, 2016). En çok tezin hazırlandığ 1 Gazi Üniversitesi’nden 10, en çok tezin hazırlandığı eğitim bilimleri enstitüsünden 29 tez çalışması araştırmaya dâhil edilmiştir.

Araştırma sonuçlarına göre tezlerde en sık kullanılan uygulamaların öğretici yazılımlar, DMY ve BCS olduğu görülmektedir. Yapılan çalışmalar incelendiğinde de görülmektedir ki; oyun ve benzeri öğretim yazılımları (Ada \& Kurtuluş, 2008), web siteleri (Akbulut \& Karakuş, 2008), DMY (Baki, Kösa, \& Güven, 2011) ve BCS (Dost, Sağlam, \& Uğur, 2011) gibi uygulamalar BDMÖ ile ilgili en sık araştırılan başlıklardır.

Konu ile ilgili öneriler ile ilgili olarak, öncelikle bu çalışma sonuçları bundan sonra yapılacak çalışmalara 1 şı tutması açısından önemli veriler sunmaktadır. Lisansüstü tez çalışmaları ile sınırlı olan bu çalışmanın benzerlerinin akademik makaleleri, kitapları ve bildirileri kapsayacak şekilde tekrar edilmesi araştırma sonucunda önerilebilir. Meta-analiz ve içerik analizi gibi farklı analiz çalışmalarının da konu üzerinde yapılması önerilebilecek başka bir tespit olarak yer verilebilir. Araştırma sonucunda lisansüstü tez çalışmalarında kullanılmış olan bilgisayar uygulamaları belirlenmeye çalışılmıştır. Yapılacak yeni çalışmalarda kullanılabilecek uygulamaya karar verirken bu bulgularında incelenmesi önerilebilir. 


\section{Summary}

Introduction: The number of the published research of Turkish educators has regularly been increasing in both national and international literature. According to Social Science Citation Index (SSCI) the number papers, addressed Turkey, published in international journals between 1997 and 2014, is over four thousands. The number of these publications has significantly been appeared since 2001 and increased up to 2012 that is a peak point for educational research papers in Turkey (Çalık \& Sözbilir, 2014, p.33). Furthermore, in another extensive analysis of educational research, it is reported that Turkey's performance in educational research publication reached up to 3rd in 2011 while it was 33th in 1990-1994 period. In 2005-2009 periods, the significant shift is evident with the rank order of 6th out of 148 countries under investigation (Tseng, Chang, Tutwiler, Lin, and Barufaldi, 2013).

Because of this growing body of educational research publications it is necessary to conduct further analysis. For this reason, some special issues have been published "to provide foresights for the future studies by evaluating the effects of a growing body of Turkish educational researches" (Çalık \& Sözbilir, 2014, p.33). These systematical review studies, content analysis, are generally defined as "systematic coding of qualitative or quantitative data based on specific themes or categories" (Dinçer, 2018). The content analysis studies are generally grouped under three sub-titles; descriptive content analysis, meta-synthesis (thematic content analysis) and meta-analysis. Thereby, it is also recommended to perform some systematical investigations about Turkey addressed researches in sub-disciplines and subjects of educational sciences. One of the most common subject in education literature especially in mathematics education literature is computer assisted mathematics teaching (Çiltaş, 2012; Çiltaş, Güler, \& Sözbilir, 2012; Ulutaş \& Ubuz, 2008).

In mathematics teaching and learning process the technological application, in particular computer-aided teaching environments, offers many advantages in teaching mathematics (Baki \& Güveli, 2008). In recent years, especially after the FATIH (Movement to Improve Opportunities and Technological Improvement) project in 2010, educators and researchers have focused on the impact of technology, specifically computers, in mathematics education (Pamuk et all., 2013).

Purpose of the Study: The overall aim of the study is to conduct a thematic content analysis (meta-synthesis) of theses and dissertations, focusing on computer assisted mathematics teaching, completed in Turkey between 1993 and 2016. The answers to the following research questions are discussed accordingly:

1. How is the distribution of theses and dissertations according to the type and the publication year?

2. How is the distribution of theses and dissertations according to the universities and the institutes?

3. How is the distribution of computer applications used in theses and dissertations as computer assisted mathematics teaching method?

Method: Thematic content analysis (meta-synthesis) which is one of the content analysis methods is employed as the research methodology in this study. The content 
analysis is generally grouped under three sub-headings "meta-analysis, meta-synthesis and descriptive content analysis". Thematic content analysis (meta-synthesis) is identified as "a systematic review that synthesizes and criticizes the results of studies conducted in a specific content area by creating themes or matrixes" (Çalık \& Sözbilir, 2014).

A total of 64 master theses and doctoral dissertations completed in Turkey between 1993 and 2016 were included in descriptive content analysis process. Theses and dissertations were examined based on some variables: year of publication, type, university, institution and used computer applications. The results of descriptive content analysis were presented by tables including frequencies and percentages.

Findings, Results \& Recommendations: As a result of conducted thematic content analysis (meta-synthesis) in the study, it was found that majority of theses and dissertations were presented after the year 2008. Similar results are also observed in some other researches (Açıkgül \& Aslaner, 2014; Demir \& Başol, 2014). It has been also determined that $85.9 \%$ of a total of 64 studies, examined in descriptive content analysis, are master theses (55 studies) and $45.3 \%$ of all studies are submitted to graduate school of educational science (29 studies). Gazi, Ankara and Marmara Universities are the most popular universities in terms of the number of published theses and dissertations. In addition, computer software for teaching mathematics, computer algebra systems (CAS) and dynamic mathematics software (DMS) were used most commonly as a computer assisted application in theses and dissertations.

According to the obtained results of this study, it is firstly suggested that beside of theses and dissertations, papers and articles should also be included in future studies on computer assisted mathematics teaching. Furthermore, these systematical review studies on computer assisted mathematics teaching; descriptive content analysis, meta-synthesis (thematic content analysis) and meta-analysis should be carried out periodically for refreshing the understanding of the literature on the subject. 


\section{Kaynakça}

Açıkgül, K., \& Aslaner, R. (2014). Bilgisayar destekli öğretim ve matematik öğretmen adaylar1: Bir literatür incelemesi. Inönü Üniversitesi Ĕ̆itim Bilimleri Enstitü Dergisi, 1(1), 41-51.

Ada, T., \& Kurtuluş, A. (2008). Öklidyen olmayan geometrinin öğretiminde bir araç olarak simcity oyununun kullanımı. VIII. International Educational Technology Conference. 6-9 May, Anadolu Üniversitesi, Eskişehir.

Akbulut, Ö. E., \& Karakuş, F. (2008). Öğretim amaçlı geliştirilen bir web sitesi hakkında öğretmen adaylarının görüşleri. VIII. International Educational Technology Conference. 6-9 May, Anadolu Üniversitesi, Eskişehir.

Baki, A. (2002). Öğrenen ve ögretenler için bilgisayar destekli matematik. İstanbul: Ceren Yayınları.

Baki, A., \& Güveli E. (2008). Evaluation of a web based mathematics teaching material on the subject of functions. Computers \& Education, 51, 854-863

Baki, A., Kösa, T., \& Güven, B. (2011). A Comparative study of the effects of dynamic geometry software and physical manipulatives on pre-service mathematics teachers' spatial visualization skills. British Journal of Educational Technology, 42(2), 291-310.

Çalık, M., \& Sözbilir, M. (2014). İçerik analizinin parametreleri. Eğitim ve Bilim, 39(174), 33-38. doi: 10.15390/EB.2014.3412.

Çalık, M., \& Sözbilir, M. (2015). İçerik analizi editörlerinden. Eğitim ve Bilim, 40(178), i-ii.

Çiltaş, A. (2012). 2005-2010 yılları arasında matematik eğitimi alanında Türkiye'de yapılan yüksek lisans ve doktora tez çalışmalarının içerik analizi. The Journal of Academic Social Science Studies, 5(7), 211-228.

Çiltaş, A., Güler, G., \& Sözbilir, M. (2012). Türkiye'de Matematik Eğitimi Araştırmaları: Bir İçerik Analizi Çalışması. Educational Sciences: Theory \& Practice, 12(1), 565-580.

Demir, S., \& Başol, G. (2014). Bilgisayar destekli matematik öğretiminin (BDMÖ) akademik başarıya etkisi: Bir meta analiz çalışması. Kuram ve Uygulamada Ĕ̆itim Bilimleri 14(5), 2013-2035.

Dinçer, S. (2018). Eğitim bilimleri araştırmalarında içerik analizi: Meta-analiz, metasentez, betimsel içerik analizi. Bartın Üniversitesi Eğitim Fakültesi Dergisi, 7(1), 176-190.

Dost, Ş., Sağlam, Y., \& Uğur, A.A. (2011). Üniversitede matematik öğretiminde bilgisayar cebiri sistemlerinin kullanımı: Bir öğretim deneyi. Hacettepe Üniversitesi Ĕ̆itim Fakültesi Dergisi, 40, 140-151.

Engin, A. O., Tösten, R., \& Kaya, M. D. (2010). Bilgisayar destekli eğitim. Kafkas Üniversitesi Sosyal Bilimler Enstitü Dergisi, 1(5), 69-80

Ergün, M. (1998). İnternet destekli eğitim. Afyon Kocatepe Üniversitesi Sosyal Bilimler Dergisi, 1, 1-10.

Göktaş, Y., Hasançebi, F., Varısoğlu, B., Akcay, A., Bayrak, N., Baran, M., \& Sözbilir, M. (2012). Trends in educational research in Turkey: A content analysis. Educational Sciences: Theory \& Practice, 12(1), 443-460. 
Gürsoy, K. (2017). Bilgisayar destekli matematik öğretiminin akademik başartya ve matematik dersine yönelik tutuma etkisi: Bir meta-analiz ve meta-sentez çalışması (Yayımlanmamış Yüksek Lisans Tezi). Karadeniz Teknik Üniversitesi, Eğitim Bilimleri Enstitüsü, Trabzon.

Hyman, R. A. (1982). Charles Babbage: Pioneer of the computer. Princeton: Princeton University Press.

Kutluca, T., Haciömeroğlu, G., \& Gündüz, S. (2016). Türkiye'de bilgisayar destekli matematik öğretimini temel alan çalışmaların değerlendirilmesi. Eğitimde Kuram ve Uygulama, 12(6), 1253-1272.

Özçep, F., Karabulut, S., Alpaslan, N., Makaroğlu, Ö., Özçep, T., \& Çağlak, F. (2003). Mühendislik felsefesi ve tarihsel gelişimi. Mühendislik Bilimleri Genç Araştırmacılar I. Kongresi, Bildiriler Kitabı. içinde (ss. 649-657). 17-20 Şubat 2003, İstanbul.

Singh, A., \& Singh, S. (2016). A comparative study of early V/S modern computers. International Journal of Advanced Research in Computer Science, 7(6), 180-184.

Tatar, E., \& Tatar, E. (2008). Fen bilimleri ve matematik eğitimi araştırmalarının analizi II: Anahtar Kelimeler. İn̈nü Üniversitesi Eğitim Fakültesi Dergisi, 9(16), 89-103.

TDK. (2018). Güncel Türkçe sözlük. Erişim adresi: http://www.tdk.gov.tr/index.php?option=com_gts\&view=gts

Tseng, Y.H., Chang, C.Y., Tutwiler, M.S., Lin, M.C., \& Barufaldi, J.P. (2012). Scientometric analysis of the effectiveness of Taiwan's educational research projects. Scientometrics, 95(3), 1141-1166. DOI 10.1007/s11192-013-0966-z.

TÜİK. (2017). Hanehalkı bilişim teknolojileri kullanım araştırması. Erişim adresi: http://www.tuik.gov.tr/PreTablo.do?alt_id=1028

Ulutaş, F., \& Ubuz, B. (2008). Research and trends in mathematics education: 2000 to 2006. Elementary Education Online, 7(3), 614-626. 


\section{EK-1: Çalışma Kapsamında İncelenen Tezlerin Listesi}

Alabay, E. (2006). Altı yaş okulöncesi dönemi çocuklarına bilgisayar destekli matematiksel kavramların öğretimi (Yayımlanmamış Yüksek Lisans Tezi). Selçuk Üniversitesi, Sosyal Bilimler Enstitüsü, Konya.

Altın, S. (2012). Bilgisayar destekli dönüşüm geometrisi öğretiminin 8. sınıf ögrencilerinin başarısına ve matematik dersine yönelik tutumuna etkisi (Yayımlanmamış Yüksek Lisans Tezi). Eskişehir Osmangazi Üniversitesi, Eğitim Bilimleri Enstitüsü, Eskişehir.

Aktümen, M. (2002). İlköğretim 8.sınıflarda harfli ifadelerle işlemlerin öğretiminde bilgisayar destekli ögretimin rolü ve bilgisayar destekli ögretim üzerin ögrenci görüşlerinin değerlendirilmesi (Yayımlanmamış Yüksek Lisans Tezi). Kastamonu Üniversitesi, Eğitim Bilimleri Enstitüsü, Kastamonu.

Andiç, T. (2012). İlköğretim 8. sınıf matematik dersi permütasyon kombinasyon konusunun bilgisayar destekli öğretiminin ögrenci erişi düzeylerine ve tutumlarına etkisi (Yayımlanmamış Yüksek Lisans Tezi). Yeditepe Üniversitesi, Sosyal Bilimler Enstitüsü, İstanbul.

Aslan, A. (2005). İlköğretim 6.sınıf matematik dersinin, ondalık kesirler ünitesinin ögretiminde bilgisayar destekli ögretimin rolü (Yayımlanmamış Yüksek Lisans Tezi). Gazi Üniversitesi, Eğitim Bilimleri Enstitüsü, Ankara.

Babapour Golezani, A. (2012). Bilgisayar destekli matematik öğretiminin lisans ögrencilerinin matematik algllarına etkisi (K.K. Ĕ̈itim Fakültesi İlköğretim Matematik Bölümü Örneği) (Yayımlanmamış Yüksek Lisans Tezi). Atatürk Üniversitesi, Eğitim Bilimleri Enstitüsü, Erzurum.

Bağçıvan, B. (2005). İlköğretim yedinci sınıfta bilgisayar destekli geometri öğretimi (Yayımlanmamış Yüksek Lisans Tezi). Uludağ Üniversitesi, Sosyal Bilimler Enstitüsü, Bursa.

Bayraktar, E. (1988). Bilgisayar destekli matematik öğretimi (Yayımlanmamış Doktora Tezi). Ankara Üniversitesi, Sosyal Bilimler Enstitüsü, Ankara.

Bayraktar-Güveli, E. (1998). Matematik öğretmenlerinin bilgisayar destekli matematik ögretimi deneyimleri (Yayımlanmamış Yüksek Lisans Tezi). Karadeniz Teknik Üniversitesi, Fen Bilimleri Enstitüsü, Trabzon.

Bayturan, S. (2011). Ortaöğretim matematik ĕgitiminde bilgisayar destekli ögrretimin, ögrencilerin başarılarl, tutumlarl ve bilgisayar öz -yeterlik algıları üzerindeki etkisi (Yayımlanmamış Doktora Tezi). Dokuz Eylül Üniversitesi, Eğitim Bilimleri Enstitüsü, İzmir.

Boyraz, Ş. (2008). Bilgisayar destekli öğretimin yedinci sınıf ögrencilerin uzamsal düşünebilme becerilerine, matematik, teknoloji ve geometri tutumlarına etkisi (Yayımlanmamış Yüksek Lisans Tezi). Orta Doğu Teknik Üniversitesi, Sosyal Bilimler Enstitüsü, Ankara.

Budak, S. (2010). Çokgenler konusunun bilgisayar destekli öğretiminin 6. Sınıf ögrencilerinin akademik başarllarına ve bilgisayar destekli geometri öğretimine yönelik tutumlarına etkisi (Yayımlanmamış Yüksek Lisans Tezi). Eskişehir Osmangazi Üniversitesi, Fen Bilimleri Enstitüsü, Eskişehir. 
Çevik, G. (2015). Lineer cebir uygulamalarının bilgisayar destekli görselleştirilmesinin, ögretmen adaylarının farkındalıklarına, görselleştirmelerine etkisi ve memnuniyeti (Yayımlanmamış Yüksek Lisans Tezi). Atatürk Üniversitesi, Eğitim Bilimleri Enstitüsü, Erzurum.

Çubuk, Ş. (2004). Matematik öğretiminde "permütasyon ve olasılı"k konusunun bilgisayar destekli öğretim materyalleri ile öğretilmesinin öğrenci başarısına etkisi (Yayımlanmamış Yüksek Lisans Tezi). Marmara Üniversitesi, Eğitim Bilimleri Enstitüsü, İstanbul.

Efendioğlu, A. (2006). Anlamlı öğrenme kuramına dayalı olarak hazırlanan bilgisayar destekli geometri programının ilköğretim dördüncü sınıf ögrencilerinin akademik başarılarına ve kalıcılığa etkisi (Yayımlanmamış Yüksek Lisans Tezi). Çukurova Üniversitesi, Sosyal Bilimler Enstitüsü, Adana.

Egelioğlu, H. C. (2008). Dönüşüm geometrisi ve dörtgensel bölgelerin alanlarının alt ögrenme alanının öğretilmesinde bilgisayar destekli ögretimin başarlya ve epistemolojik inanca etkisi (Yayımlanmamış Yüksek Lisans Tezi). Marmara Üniversitesi, Eğitim Bilimleri Enstitüsü, İstanbul.

Erdoğan, N. (2014). Matematik öğretmen adaylarının bilgisayar destekli matematik ögretimi dersi kapsamında teknolojik pedagojik alan bilgilerinin gelişimi (Yayımlanmamış Yüksek Lisans Tezi). Boğaziçi Üniversitesi, Sosyal Bilimler Enstitüsü, İstanbul.

Erdoğan, Y. (2000). Bilgisayar destekli kavram haritalarının matematik öğretiminde kullanılması (Yayımlanmamış Yüksek Lisans Tezi). Marmara Üniversitesi, Fen Bilimleri Enstitüsü, İstanbul.

Erkuş, Y. (2014). Illköğretim matematik öğretmen adaylarının bilgisayar destekli eğitim yapmaya yönelik görüşlerinin belirlenmesi ve Geometer's Sketchpad yazılımını ögrenme süreçlerinin değerlendirilmesi (Yayımlanmamış Yüksek Lisans Tezi). Erzincan Üniversitesi, Fen Bilimleri Enstitüsü, Erzincan.

Ersoy, M. (2009). Bilgisayar destekli ders uygulamalarının ilkögrretim matematik ögretmeni adaylarının geometri başarllarına etkisi ve öğrenme ve ögretmeye yönelik görüşleri (Yayımlanmamış Yüksek Lisans Tezi). Eskişehir Osmangazi Üniversitesi, Fen Bilimleri Enstitüsü, Eskişehir.

Ertem Akbaş, E. (2016). Meslek yüksekokulu öğrencilerinin bilgisayar destekli ortamda "limit-süreklilik" konusundaki öğrenmelerinin solo taksonomisine göre değerlendirilmesi (Yayımlanmamış Yüksek Lisans Tezi). Karadeniz Teknik Üniversitesi, Eğitim Bilimleri Enstitüsü, Trabzon.

Faydac1, S. (2008). İlköğretim 6. sinıf öğrencilerine geometrik dönüşümlerden öteleme kavramının bilgisayar destekli ortamda öğretiminin incelenmesi (Yayımlanmamış Yüksek Lisans Tezi). Gazi Üniversitesi, Eğitim Bilimleri Enstitüsü, Ankara.

Fırat, S. (2011). Bilgisayar destekli eğitsel oyunlarla gerçekleştirilen matematik ögretiminin kavramsal ögrenmeye etkisi (Yayımlanmamış Yüksek Lisans Tezi). Adıyaman Üniversitesi, Fen Bilimleri Enstitüsü, Adıyaman.

Gelibolu, M. F. (2008). Gerçekçi matematik eğitimi yaklaşımıyla geliştirilen bilgisayar destekli mantı öğretimi materyallerinin 9. sinıf matematik dersinde 
uygulanmasının değerlendirilmesi (Yayımlanmamış Yüksek Lisans Tezi). Ege Üniversitesi, Fen Bilimleri Enstitüsü, İzmir.

Gençoğlu, T. (2013). Geometrik cisimlerin yüzey alanları ve hacmi konularının ögretiminde bilgisayar destekli ögrretim ile akıll tahta destekli öğretimin öğrenci akademik ve matematiğe ilişkin tutumuna etkisi (Yayımlanmamış Yüksek Lisans Tezi). Gazi Üniversitesi, Eğitim Bilimleri Enstitüsü, Ankara.

Gürkaynak, G. (2015). Bilgisayar destekli matematik dersinin Mathematica yazılımı ile işlenmesine yönelik durum çalışması (Yayımlanmamış Yüksek Lisans Tezi). Atatürk Üniversitesi, Eğitim Bilimleri Enstitüsü, Erzurum.

Hangül, T. (2010). Bilgisayar destekli ögrretimin 8. sinıf matematik ögretiminde öğrenci tutumuna etkisi ve BDÖ hakkında öğrenci görüşleri (Yayımlanmamış Yüksek lisans Tezi). Balıkesir Üniversitesi, Fen Bilimleri Enstitüsü, Balıkesir.

Helvacı, B. T. (2010). Bilgisayar destekli öğretimin, ilköğretim 6. sinıf öğrencilerinin matematik dersi "çokgenler" konusundaki akademik başarılarına ve tutumlarına etkisi (Yayımlanmamış Yüksek lisans Tezi). Gazi Üniversitesi, Eğitim Bilimleri Enstitüsü, Ankara.

İçel, R. (2011). Bilgisayar destekli öğretimin matematik başarısına etkisi: Geogebra örneği (Yayımlanmamış Yüksek Lisans Tezi). Selçuk Üniversitesi, Eğitim Bilimleri Enstitüsü, Konya.

Kağızmanlı, T. B. (2015). Analitik geometriye yönelik bilgisayar destekli işbirlikli dinamik öğrenme ortamının geliştirilmesi, uygulanması ve değerlendirilmesi (Yayımlanmamış Doktora Tezi). Atatürk Üniversitesi, Eğitim Bilimleri Enstitüsü, Erzurum.

Kapucu, T. (2016). Bilgisayar destekli eğitimin 8. sinıf öğrencilerinin permütasyonkombinasyon-olasılık başarısına ve ögrencilerin bilgisayar destekli ĕgitime ilişkin tutumları (Yayımlanmamış Yüksek Lisans Tezi). ODTÜ, Doğal ve Uygulamalı Bilimler Enstitüsü, Ankara.

Karakış, H. (2014). İlköğretim 4. Sınıf "kesirler” ünitesi için geliştirilen bilgisayar destekli etkinliklerin öğrenci başarı ve tutumuna etkisi (Yayımlanmamış Yüksek Lisans Tezi). Balıkesir Üniversitesi, Fen Bilimleri Enstitüsü, Balıkesir.

Karakuş, Ö. (2008). Bilgisayar destekli dönüşüm geometrisi öğretiminin öğrenci erişisine etkisi (Yayımlanmamış Yüksek Lisans Tezi). Eskişehir Osmangazi Üniversitesi, Fen Bilimleri Enstitüsü, Eskişehir.

Kesicioğlu, O. S. (2011). Doğrudan öğretim yöntemiyle hazırlanan ĕgitim programının ve bu yönteme göre hazırlanan bilgisayar destekli eğitim programının okul öncesi çocuklarının geometrik şekil kavramlarını öğrenmelerine etkisinin incelenmesi (Yayımlanmamış Doktora Tezi). Gazi Üniversitesi, Eğitim Bilimleri Enstitüsü, Ankara.

Korucu, S. (2009). Çokgenler konusunda karikatür ve bilgisayar destekli öğretim yöntemlerinin karşılaştırılması (Yayımlanmamış Yüksek Lisans Tezi). Marmara Üniversitesi, Eğitim Bilimleri Enstitüsü, İstanbul.

Kutlu, M. O. (1999). Öğretimi ayrıntılama kuramına dayalı matematik öğretimi ve bilgisayar destekli sunumun başarıya ve kalıcılığa etkisi (Yayımlanmamış Yüksek Lisans Tezi). Çukurova Üniversitesi, Sosyal Bilimler Enstitüsü, Adana. 
Kutluca, T. (2009). İkinci dereceden fonksiyonlar konusu için tasarlanan bilgisayar destekli öğrenme ortamının değerlendirilmesi (Yayımlanmamış Doktora Tezi). Karadeniz Teknik Üniversitesi, Fen Bilimleri Enstitüsü, Trabzon.

Küslü, F. (2015). Bilgisayar destekli matematik öğretiminin 8.sinif ögrencilerinin "prizmalar" konusundaki başarısına etkisi (Yayımlanmamış Yüksek Lisans Tezi). Sakarya Üniversitesi, Eğitim Bilimleri Enstitüsü, Sakarya.

Malaş, H. (2011). Bilgisayar destekli matematik dersinde star stratejilerinin ilkögretim 2. sınıf ögrencilerinin matematik dersi başarlları ve problem çözme becerileri üzerindeki etkisi (Yayımlanmamış Yüksek Lisans Tezi). Ege Üniversitesi, Fen Bilimleri Enstitüsü, İzmir.

Mutlu, Y. (2016). Bilgisayar destekli öğretim materyallerinin matematik öğrenme güçlüğü yaşayan öğrencilerin sayı algılama becerileri üzerindeki etkilerinin incelenmesi (Yayımlanmamış Doktora Tezi). Atatürk Üniversitesi, Eğitim Bilimleri Enstitüsü, Erzurum.

Önder, F. (2000). Bilgisayar destekli geometri öğretiminin ilköğretim öğrencilerinin başarısı üzerine etkilerinin araştırılması (Yayımlanmamış Yüksek Lisans Tezi). Selçuk Üniversitesi, Fen Bilimleri Enstitüsü, Konya.

Özdoğan, E. (2008). İşbirlikli öğrenme yönteminin ilköğretim 4. sınıf matematik ögretiminde öğrenci tutum ve başarısına etkisi: Bilgisayar destekli işbirlikli ögrenme ve küme destekli bireyselleştirme tekniği (Yayımlanmamış Yüksek Lisans Tezi). Ege Üniversitesi, Sosyal Bilimler Enstitüsü, İzmir.

Öztürk, G. (2005). Illköğretim 8. sinıf düzeyinde permütasyon ve olasılık ünitesinin bilgisayar destekli tasarımı (Yayımlanmamış Yüksek Lisans Tezi). Balıkesir Üniversitesi, Fen Bilimleri Enstitüsü, Balıkesir.

Öztürk, M. (2011). Bilgisayar destekli öğretim yönteminin oran orantı konusunun ögretiminde akademik başarıya etkisi (Yayımlanmamış Yüksek Lisans Tezi). Atatürk Üniversitesi, Eğitim Bilimleri Enstitüsü, Erzurum.

Öztürk, T. (2011). Matematik öğretiminde bilgisayar destekli öğretim yöntemiyle hazırlanan animasyon tekniğinin kullanımı (Yayımlanmamış Yüksek Lisans Tezi). Firat Üniversitesi, Fen Bilimleri Enstitüsü, Elazığ.

Pilli, O. (2008). The effects of computer-assisted instruction on the achievement, attitudes and retention of fourth grade mathematics course (Unpublished Doctoral Dissertation). University of Middle East Technical, Ankara, Turkey.

Sakallı, A. N. (2013). Bilgisayar destekli proje tabanlı öğretim yaklaşımına göre hazırlanmış bir dersin öğrencilerin ders başarılarına ve tutumlarına etkisinin belirlenmesi ve ögrenci görüşlerine yansıması (matematik dersi örneği) (Yayımlanmamış Yüksek Lisans Tezi). Gazi Üniversitesi, Eğitim Bilimleri Enstitüsü, Ankara.

Selim, Y. (2009). Matematik öğretmen adaylarının bilgisayar destekli olarak hazırladıkları ögretim materyalinin niteliği ile matematik ve ögretmenlik meslek bilgileri arasındaki ilişkinin incelenmesi (Yayımlanmamış Doktora Tezi). Atatürk Üniversitesi, Fen Bilimleri Enstitüsü, Erzurum. 
Sulak, S. A. (2002). Matematik dersinde bilgisayar destekli öğretimin öğrenci başarı ve tutumlarına etkisi (Yayımlanmamış Yüksek Lisans Tezi). Selçuk Üniversitesi, Fen Bilimleri Enstitüsü, Konya.

Şataf, H. A. (2009). Bilgisayar destekli matematik ögretiminin ilköğretim 8. sinıf ögrencilerinin "dönüşüm geometrisi” ve “üçgenler” alt öğrenme alanındaki başarısı ve tutuma etkisi (Isparta örneği) (Yayımlanmamış Yüksek Lisans Tezi). Sakarya Üniversitesi, Sosyal Bilimler Enstitüsü, Sakarya.

Şen, N. (2010). İlköğretim altıncı sınıf matematik dersinde bilgisayar destekli sezgisel düşünme kontrollü olasılık ögretiminin öğrencilerin akademik başarı ve sezgisel düşünme düzeylerine etkisi (Yayımlanmamış Yüksek Lisans Tezi). Çukurova Üniversitesi, Sosyal Bilimler Enstitüsü, Adana.

Tabuk, M. (2003). Illköğretim 7. sinıflarda daire ve silindir konusunun öğretiminde bilgisayar destekli öğretimin başarıya etkisi (Yayımlanmamış Yüksek Lisans Tezi). Marmara Üniversitesi, Eğitim Bilimleri Enstitüsü, İstanbul.

Takunyac1, M. (2007). İlköğretim 8.sınıf öğrencilerinin geometri başarısında bilgisayar destekli öğretimin etkisi (Yayınlanmamış Yüksek Lisans Tezi). Sakarya Üniversitesi, Sosyal Bilimler Enstitüsü, Sakarya.

Taşlıbeyaz, E. (2010). Ortaöğretim öğrencilerinin bilgisayar destekli matematik ögretiminde matematik algılarına yönelik durum çalışması: Lise 3. sınıf uygulaması (Yayımlanmamış Yüksek Lisans Tezi). Atatürk Üniversitesi, Fen Bilimleri Enstitüsü, Erzurum.

Tayan, E. (2011). Doğrusal denklemler ve grafiklerinin öğretiminde bilgisayar destekli ögretim yönteminin başarıya etkisi (Yayımlanmamış Yüksek Lisans Tezi). Atatürk Üniversitesi, Eğitim Bilimleri Enstitüsü, Erzurum.

Tunçer, D. (1993). Bilgisayara dayalı grup ve bireysel problem çözme ortamının ögrencilerin matematik başarısı, matematik ve bilgisayar destekli öğretime olan tutumları üzerindeki etkisi (Yayımlanmamış Yüksek Lisans Tezi). Orta Doğu Teknik Üniversitesi, Fen Bilimleri Enstitüsü, Ankara.

Turhan, E. İ. (2010). Bilgisayar destekli perspektif çizimlerin sekizinci sinıf öğrencilerinin uzamsal yeteneklerine, matematik, teknoloji ve geometriye karsı tutumlarına etkisi (Yayımlanmamış Yüksek Lisans Tezi). Eskişehir Osmangazi Üniversitesi, Fen Bilimleri Enstitüsü, Eskişehir.

Uygun, M. (2008). Bilgisayar destekli bir ögretim yazllımının ilköğretim 4. sinıf öğrencilerinin kesirler konusundaki başarl ve matematiğe karşı tutumuna etkisinin incelenmesi (Yayımlanmamış Yüksek Lisans Tezi). Abant İzzet Baysal Üniversitesi, Sosyal Bilimler Enstitüsü, Bolu.

Uzun, N. (2013). Dinamik geometri yazılımlarının bilgisayar destekli ögretim ve akıllı tahta ile zenginleştirilmiş öğrenme ortamlarında kullanımının öğrencilerin akademik başarısına, uzamsal görselleştirme becerisine ve uzamsal düşünme becerisine ilişkin tutumlarına etkisi (Yayımlanmamış Yüksek Lisans Tezi). Gazi Üniversitesi, Eğitim Bilimleri Enstitüsü, Ankara

Yechshzhanova, Z. (2014). Bilgisayar destekli öğretim ve mobil öğretim için geometri dersinin içeriğinin geliştirilmesi (Yayımlanmamış Yüksek Lisans Tezi). Gazi Üniversitesi, Bilişim Enstitüsü, Ankara. 
Yıldız, Z. (2009). Geometrik cisimlerin yüzey alanlarl ve hacimleri konularında bilgisayar destekli ögretimin ilköğretim 8. sinıf öğrenci tutumu ve başarısına etkisi (Yayımlanmamış Yüksek Lisans Tezi). Gazi Üniversitesi, Eğitim Bilimleri Enstitüsü, Ankara.

Yiğit, A. (2007). İlköğretim 2. sinıf seviyesinde bilgisayar destekli ĕgitici matematik oyunlarının başarıya ve kalıcılığa etkisi (Yayımlanmamış Yüksek Lisans Tezi). Çukurova Üniversitesi, Sosyal Bilimler Enstitüsü, Adana.

Yücesan, C.(2011). Bilgisayar destekli öğretimin 6.sınıf kümeler konusunda öğrenci başarısına etkisi (Yayımlanmamış Yüksek Lisans Tezi). Rize Üniversitesi, Sosyal Bilimler Enstitüsü, Rize.

Yünkül, E. (2006). Illköğretim 6. sinıf matematik dersi OBEB ve OKEK konusunda bilgisayar destekli ögretim tasarımı (Yayımlanmamış Yüksek Lisans Tezi). Balıkesir Üniversitesi, Fen Bilimleri Enstitüsü, Balıkesir. 


\section{EK-2: Tez İnceleme Formu}

\begin{tabular}{|c|c|c|}
\hline \multicolumn{3}{|l|}{ Tezin Başlığg } \\
\hline \multicolumn{3}{|l|}{ Tezin Yazarı } \\
\hline \multicolumn{3}{|l|}{ Tezin Y1l1 } \\
\hline \multicolumn{3}{|l|}{ Hazırlandığı Üniversite } \\
\hline Hazırlandığ1 Enstitü & \begin{tabular}{|l} 
Eğitim Bilimleri \\
$\square$ Fen Bilimleri
\end{tabular} & $\square$ Eğitim Bilimleri \\
\hline Tezin Sayfa Sayısı & $\begin{array}{l}\square \\
\square-100 \\
\square\end{array}$ & $\begin{array}{l}201-300 \square 401-500 \\
301-400\end{array}$ \\
\hline Tezin Danışman Unvanı & $\begin{array}{l}\text { Prof. Dr. } \\
\text { Doç. Dr. } \\
\text { Belirtilmemiş }\end{array}$ & $\begin{array}{ll}\square & \text { Yrd. Doç. Dr } \\
\square \text { Dr. }\end{array}$ \\
\hline Örneklem Düzeyi & $\begin{array}{l}\text { Okul Öncesi } \\
\text { Illkokul } \\
\text { Ortaokul } \\
\text { Diğer }\end{array}$ & $\begin{array}{l}\square \text { Lise } \\
\square \text { Lisans } \\
\square \text { Öğretmen }\end{array}$ \\
\hline Örneklem Büyüklüğü & 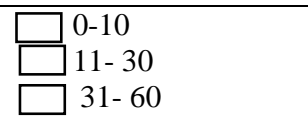 & $\begin{array}{c}\square 1-100 \\
101-500 \\
\square>500\end{array}$ \\
\hline Araştırmanın Yöntemi & \begin{tabular}{|l|} 
Nitel Yöntem \\
Nicel Yöntem
\end{tabular} & $\begin{array}{l}\text { Karma Yöntem } \\
\text { Nitel + Nicel Yöntem }\end{array}$ \\
\hline Araştırmanın Deseni & $\begin{array}{l}\text { Deneysel } \\
\square \text { Durum Çalışması }\end{array}$ & $\begin{array}{l}\text { Tarama } \\
\square \text { Meta Analiz }\end{array}$ \\
\hline Veri Toplama Aracı & $\begin{array}{l}\square \text { Anket } \\
\square \text { Görüşme } \\
\square \text { Diğer }\end{array}$ & \begin{tabular}{|l|l} 
Ölçek \\
Başarı Testi
\end{tabular} \\
\hline Uygulama Alanı & $\begin{array}{l}\square \text { Matematik } \\
\square \text { Geometri }\end{array}$ & $\square$ Karma \\
\hline
\end{tabular}

This is an Open Access article distributed under the terms of the Creative CommonsAttributionNonCommercial-ShareAlike 4.0 International (CC BY-NC-SA 4.0). For further information, you can refer to https://creativecommons.org/licenses/by-nc-sa/4.0/ 